\title{
Analysis of the application of virtual reality in sports building
}

\author{
Tianjiao $\mathrm{Li}^{1}$, a , Bin $\mathrm{Li}^{2, \mathrm{~b}}$ Guowei Liu ${ }^{3, \mathrm{c}}$ \\ 1 JiLin JianZhu University, ChangChun, China \\ 2JiLin JianZhu University, ChangChun, China \\ ${ }^{3}$ South China University of Technology,GuangZhou,China \\ a490752012@qq.com, b445453185@qq.com, c723141359@qq.com
}

\begin{abstract}
Keywords: virtual reality;sports building;application.
Abstract. With the maturity and development of virtual reality technology, more and more people use virtual reality technology to expand the life in different areas, the major manufacturers also produced a corresponding different equipment to promote and improve the virtual reality technology to bring people different experience. Virtual reality technology can be applied in many aspects of life. It can be said that the development and improvement of virtual reality technology is inevitable in the Internet age, and even can be extended and spread to all aspects of human daily life, as the same as the computer and mobile phone. In this paper, the virtual reality technology used in sports building simulation and hypothesis, trying to knock the door of virtual reality technology in the application of sports building to promote more experts and scholars based on this research and exploration.
\end{abstract}

\section{Introduction}

Virtual reality technology is a kind of computer simulation system which can create and experience virtual world. It uses computer to generate a simulation environment. Interactive 3D dynamic visual and physical behavior simulation makes users immersed in the Environment. Virtual Reality Technology mainly includes simulation environment, perception, natural skills and sensing equipment and so on. The simulation environment is a computer generated, real-time dynamic three-dimensional realistic images. Perception means that the ideal VR should have all the perception of people. In addition to computer graphics technology generated by visual perception, there are hearing, touching, moving and other perception, even including the sense of smell and taste, also known as multi-perception.[1] Natural skills refer to human head movements, gestures, or other human actions, the computer to deal with the action of the participants to adapt to the data from user input to make real-time response, and feedback to the user's facial features. The sensing device is a three-dimensional interactive device.

The concept of virtual reality can be roughly divided into five stages. The first stage: before 1950s. The concept of virtual reality in a science fiction named "Pygmalion's Spectacles" written by Stanley G. Weinbaum describes a goggle-based virtual reality system with holographic recording of fictional experiences, including touch and smell. The second stage: from the 1950s to the 1970s. Morton Heilig invented a machine named Sensorama in 1957, that can give people multiple senses, include touch, sight, smell and sound. He is called the Father of Virtual Reality. Ivan Sutherland and his student Bob Sproull, invented a machine that people always think it is the first invention about virtual reality and augmented reality head-mounted display system in 1968. The third stage: from 1970s to 1990s. Lanier do a research about the virtual reality devices such like eye phones, data gloves, volume control in 1980s.[2] The fourth stage: from 1990s to 2000s. In 1995, Nintendo brought a Virtual Boy - a virtual reality home console. Although it is just a console, but through virtual reality technology to expand the space of human's experience, but because of virtual reality technology is not mature, leading to discontinued after half year. The fifth stage: from 2000s to now. Since 2000, major corporate giants have focused on the virtual reality market, such as in 2007, Google launched the Street View service, this service can show the global road, architecture and rural areas. It also has a stereoscopic 3D model; In 2014, Facebook spend 2 billion dollars bought Oculus VR, a company produce virtual reality headphone; It can be seen that the virtual reality technology from the way of imagining to achieve step by step.[3] 
However, based on the combination of virtual reality and sports building has not been put on the agenda, or just getting started. From 1896, since Athens, Greece in 1896 held its first modern Olympic Games, has been held 31 Olympic Games to now, and the 32nd Olympic Games will be held in Tokyo, Japan in 2020. Figure 1 illustrates the Japanese people's physical exercise and the relationship between the year, with the growth of the year, more and more people to participate in physical exercise, it can be said that physical exercise is a common way of life advocated around all the world, with the social progress and the gradual improvement of people's living standards, we can see that the number of people around the world to participate in the physical exercise will be increasing.

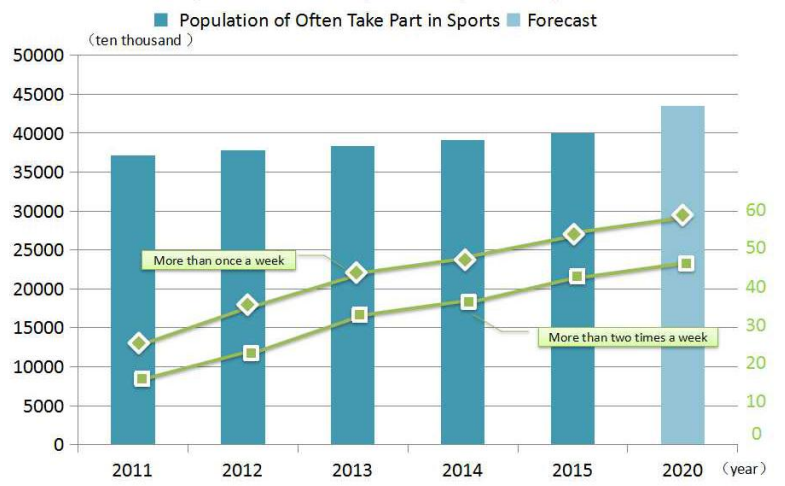

Fig. 1. Population of participation in sports in Japan

And the increase of participation in the training population will create new social problems, such as people do not have enough space to do physical exercise, or with the gradual development of the physical exercise, the way and type of exercise gradually increased, that can not meet the special needs of people, and maybe there is not enough space.[4] Such as bicycle motocross, soccer, surfing, hiking and other sports require some places for people to use, and outdoor original environment will be destroyed because of the frequency of exercise will be increasing, for indoor exercise, there maybe also unable to meet the social needs of the increasing situation. This time combined with virtual reality technology to solve the problem, and improve the development of physical exercise will become a good way.

\section{Virtual Reality Technology Characteristics and Application Necessity}

Virtual reality has four characteristics are: interactive, multi-sensory, visionary and immersion. Interactive refers to the user can according to different needs, use professional technical equipment to simulate the virtual environment to exchange and contact naturally, and even change all the things in virtual environment. Multi-sensory is limited by hardware constraints. At present, the virtual reality technology has several perceptual functions, such as hearing, touching, moving and so on, which can be more comprehensive perception of the 'real environment'.[5] Visionary refers to the virtual reality technology can simulate in real life that can be achieved or objectively imagine things that can not happen, infinite to open the human imagination. Immersion Through the interaction with the virtual scene, participants can feel the reality of the exists in the computer virtual world as a protagonist, it is just like in a real world.[6]

The four characteristics of virtual reality are applied to the support of combine virtual reality technology with sports buildings, in the process of physical exercise, many actions need to be repeated, the above four characteristics can not only make people effective for exercise, giving a comfortable environment for physical exercise, at the same time, it is easy to create and adjust the devices that just need repetitive operation.[7] So use the virtual reality technology in sports building is necessary. 


\section{Simulation of the Combination of Virtual Reality Technology and Sports Building}

As shown in Figure 2, we simulated four different kinds of sports as bicycle motocross, soccer, surfing and hiking respectively. But due to virtual reality technology equipment has not yet fully developed, We just carried out a rough simulation.[8] For the bicycle motocross, need to simulate a part of the terrain as the real site for bicycle motocross, make the terrain can change when people do sport on there, to give people the feeling as bicycle motocross. As while the corresponding 360-degree image wrapped with the people who is doing exercise, so that it can be placed in a 'real' environment, equipped with related equipment to track human movement, feedback and change timely, to achieve the perfect combination of man-machine. But also need sound equipment and air conditioning devices to create the appropriate natural environment. For soccer athletics, the equipment is similar, but need to solve the problem that can let few people team up and play together at the same time. As for surfing and hiking it also use the same principle about the equipment, just need adjust a little according to different characteristics of the sports.
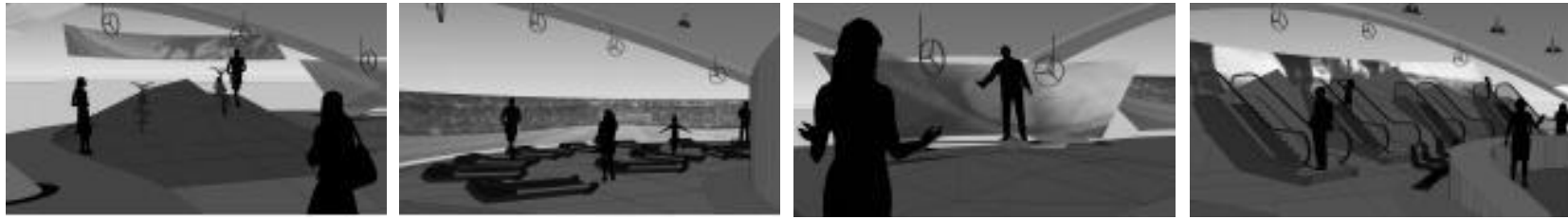

Fig. 2. Virtual Reality Simulation of different sports

It can be seen that, for these different sports, based on the virtual reality technology it is not too difficult to simulate, the key to solve the problem for simulate different scenes are similar, that means just to developed the existing virtual reality technology a little we will achieve the desired results we want to.[9]

\section{Conclusion}

The extensive application of virtual reality technology is a historical necessity, but also the inevitable outcome of the Internet age, therefore, we should hold a positive attitude to face the problem of research and development of virtual reality technology.[10] However, as the global exercise population is increasing, it presumably will bring some social problems such as insufficient space to do sports and so on. Then the combination of sports building and virtual reality technology has become a thing had to do.

Based on the combination of virtual reality and sports architecture can have the following advantages, just as the Table 1 shown. First of all, it have the benefits to solve the social problem; Then create more conditions about sports for people, for example, the simulation of the natural environment can meet people's needs of various outdoor exercise, saving people's time to go outdoor; Third, with a variety of choices of physical exercise to meet the needs of different groups of people for exercise;[11] At the same time, it can save people's money, and even reduce carbon emissions that people must drive a car far away for exercise, protect the environment; In addition, the virtual reality for the simulation of various sports activities, can analysis and monitor the movement of the process of athletes, to avoid defects and play the strengths; And virtual reality for the simulation about the scenes of sports can make sure the security of exercise people, do not need to do sports in a dangerous situation; Finally, the use of virtual reality technology combined with sports buildings to avoid the impact of natural conditions such as weather.[12]

\begin{tabular}{|c|c|c|c|c|c|c|}
\hline $\begin{array}{l}\text { solve } \\
\text { new } \\
\text { social } \\
\text { problem }\end{array}$ & $\begin{array}{l}\text { save time } \\
\text { that people } \\
\text { will waste } \\
\text { for outdoor } \\
\text { sports }\end{array}$ & $\begin{array}{l}\text { meet } \\
\text { different } \\
\text { needs of } \\
\text { people for } \\
\text { variety } \\
\text { sports }\end{array}$ & $\begin{array}{l}\text { save the } \\
\text { money that } \\
\text { people must } \\
\text { pay for } \\
\text { traffic or } \\
\text { others }\end{array}$ & $\begin{array}{l}\text { shape better } \\
\text { athletes }\end{array}$ & $\begin{array}{l}\text { make sure } \\
\text { about } \\
\text { security of } \\
\text { people }\end{array}$ & $\begin{array}{l}\text { avoid the } \\
\text { impact of } \\
\text { weather }\end{array}$ \\
\hline
\end{tabular}


All in all, the combination of virtual reality technology with sports building have more advantages than disadvantages. And also the necessity of history, it is the trend of maturity in science and technology, I hope this article can cause more scholars and experts concerned and research!

\section{Acknowledgements}

This work was financially supported by the Shanghai Natural Science Foundation (0666666), Innovation Program of Shanghai Municipal Education Commission (060000) and Shanghai Leading Academic Discipline Project of Shanghai Municipal Education Commission (0555555).

\section{References}

[1] Ball, J., Capanni, N., \& Watt, S.: International Journal of Social Sciences, 2(2), 78 - 88. Virtual reality for mutual understanding in landscape planning (2008).

[2] Boradkar, P.: In L. Pauwels, \& E.Margolis (Eds.), The Sage handbook of visual research methods (pp. 150 - 167).London: Sage Publications Ltd. Visual research methods in the design process (2014).

[3] Ye, J., Campbell, R. I., Page, T., \& Badni, K. S.: Design Studies, 27(1), 77 - 97. An investigation into the implementation of virtual reality technologies in support of conceptual design (2006).

[4] Yan, W., Culp, C., \& Graf, R.: Automation in Construction, 20, 446 - 458. Integrating BIM and gaming for real time interactive architectural visualization (2010).

[5] Simpson, D. M.: A literature review and topical bibliography. Journal of Planning Literature, 15(3), 359 - 376. Virtual reality and urban simulation in planning (2001).

[6] Silvestri, C., Motro, R., Maurin, B., \& Dresp-Langley, B.: Design Studies, 31(4), 363 - 381. Visual spatial learning of complex object morphologies through the interaction with virtual and real-world data (2010).

[7] Hansen, A., \& Machin, D.: Environmental Communication, 7(2), 151 - 168. [Special Issue].Researching visual environmental communication (2013).

[8] Gu, N., Kim, M. J., \& Maher, M. L.: Automation in Construction, 20, 270 - 278. Technological advancements in synchronous collaboration: The effects of $3 \mathrm{D}$ virtual worlds and tangible user interfaces on architectural design (2011).

[9] Gill, L., Lange, E., Morgan, E., \& Romano, D.: Environment and Planning B: Planning and Design, 40, 742 - 754. An analysis of usage of different types of visualisation media within a collaborative planning workshop environment (2013).

[10]Ervin, S. M.: Landscape and Urban Planning, 54(1 - 4), 49 - 62. Digital landscape modeling and visualization: A research agenda (2001).

[11]de Freitas, M. R., \& Ruschel, R. C.: In Proceedings of the 18th international conference on computer-aided architectural design research in Asia, (CAADRIA 2013), Hong Kong (pp. 407 416). What is happening to virtual and augmented reality applied to architecture? (2013).

[12] Orland, B., Budthimedhee, K., \& Uusitalo, J.: Landscape and Urban Planning, 54(1 - 4), 139 148. Considering virtual worlds as representations of landscape realities and as tools for landscape planning (2001). 